University of Nebraska - Lincoln

DigitalCommons@University of Nebraska - Lincoln

Faculty Publications from the Department of Electrical \& Computer Engineering, Department Electrical and Computer Engineering

$12-1975$

\title{
Optimal and Suboptimal Estimation in Differential PCM and Adaptive Predictive Coding Systems
}

Jerry Gibson

University of Nebraska-Lincoln

Follow this and additional works at: https://digitalcommons.unl.edu/electricalengineeringfacpub

Part of the Electrical and Computer Engineering Commons

Gibson, Jerry, "Optimal and Suboptimal Estimation in Differential PCM and Adaptive Predictive Coding Systems" (1975). Faculty Publications from the Department of Electrical and Computer Engineering. 103. https://digitalcommons.unl.edu/electricalengineeringfacpub/103

This Article is brought to you for free and open access by the Electrical \& Computer Engineering, Department of at DigitalCommons@University of Nebraska - Lincoln. It has been accepted for inclusion in Faculty Publications from the Department of Electrical and Computer Engineering by an authorized administrator of DigitalCommons@University of Nebraska - Lincoln. 
Published in IEEE Conference on Decision and Control including the 14th Symposium on Adaptive Processes, 1975; Vol. 14, Part 1 (Dec. 1975), p. 353; doi 10.1109/CDC.1975.270705 Copyright (C 1975 IEEE. Used by permission.

TA47

OPTIMAL AND SUBOPTIMAL ESTIMATION IN DIFFERENTIAL PCM AND ADAPTIVE PREDICTIVE CODING SYSTEMS

Jerry D. Gibson

Department of Electrical Engineering

University of Nebraska

Lincoln, Nebraska 68508

Both differential pulse code modulation (DPCM) and adaptive predictive coding (APC) systems have been used somewhat successfully for low data rate digital volce transuission. A DPCM system has as 1ts goal the removal of signal redundancy prior to transalssion by a linear prediction of the incoming signal with a weighted combination of past signal estimates. The error in the prediction process is then quantized and transmitted to the receiver. An identical prediction loop is used at the recelver to reinsert the redundancy, and hence, to reconstruct the speech signal. Both the quantizer and predictor may or way not be adaptive.

The DPCM system described above does not take advantage of the fact that the inconing signal is a speech waveform. The APC system attemps to utilize this information by subtracting out the long term redundancy prior to operating on the signal to remove the short term redundancy via a DPCM system.

The primary goal of both systems is to reduce the dynamic range of the input so that the transmitted signal can be accurately quantized and encoded with the fewest number of bits. Both of these systems attempt to accomlish this by predicting the input speech signal by a linear combination of past speech estimates. The key phrase in the preceding sentence is "... past speech estimates". That is, both systems derive their predicted value from estimates of past signal values, not the signal itself. These signal estimates, which are used in the prediction process at both the transmitter and receiver, contain unwanted quantization noise. This quantization noise has been established as the limiting factor on DPCM and APC systems performance, which are considered to be the most promising techniques presently available for digital voice transmission at 6 to $16 \mathrm{Kbits} / \mathrm{sec}$.

The continuing research described here is concerned with the reduction or elimination of quantization noise effects in the prediction loops of DPCM and APC systems by the application of optimal filtering methods. Two distinct approaches are being taken on each system. One approach consists of inserting a Kalman filter type algorithm In the feedback loop to optimally filter the quantization nolse out of the signal estimates prior to using these values for prediction. The filtering is optimal in the sense that the mean square error in the prediction of the input is minimized. The above approach assumes that some other procedure is being used to determine the feedback tap gains (predictor coefficients) Independent of the noise filtering. This is, of course, possible, and 1t may be desirable for various reasons. However, such an approach is suboptinal since the predictor coefficient calculation and filter problems cannot be decoupled.

The second approach, then, is to augment the state vector with the predictor coefficients and then use an extended Ralman filter type algorithm to accomplish the predictor coefficient calculation and noise filtering simultaneously to minimize the mean square prediction error. Although this approach is optinal, it does result in increased system complexity, since the dimension of the algorithws has now been doubled.

The filter algorithm parameters such as the message and observation noise variances and initial conditions must be selected using physical arguments and system simulations. Previous experience indicates that generally the message and observation noise variances can be assumed to be independent, with constant variances. However, in cases where these assumptions are not met, algorithms exist for adaptively identifying the required variances and for taking into account the effects of sequentially correlated observation noise. If only the observation nofse is a function of time and if only single stage noise correlation is present, (as inltial malyses indicate) a negligible increase in system complexity is required.

Preliminary performance studies have revealed that in an adaptive DPCA system operating at 12 to $18 \mathrm{Kbits} / \mathrm{sec}$. an increase in signal-to-noise ratio (SNR) of 4 to $5 \mathrm{~dB}$ is avatlable, which would result In a substantial increase in voice quality from the equivalent quality of 4 to 5 bit $P C M$ to the quality of 5 to 6 bit PCM. For the APC systems, preliminary studies indicate that elimination of the quantization noise in the prediction loop will produce an increase in SNR of 4 to $6 \mathrm{~dB}$. This would put the speech quality of a 6 to $8 \mathrm{Kbits} / \mathrm{sec}$. APC system in the "good" to "excellent" range. Analytically, it can be shown that the filtering of the quantization noise increases the improvement in SNR provided by the prediction loop. 